\title{
Solubility of Anthracene in Binary Alcohol + Dibutyl Ether Solvent Mixtures
}

\author{
Joyce R. Powell and William E. Acree, Jr.* \\ Department of Chemistry, University of North Texas, Denton, Texas 76203-0068
}

\begin{abstract}
Experimental solubilities are reported for anthracene dissolved in seven binary mixtures containing dibutyl ether with 1-propanol, 2-propanol, 1-butanol, 2-butanol, 1-octanol, 2-methyl-1-propanol, and 3-methyl1-butanol at $25^{\circ} \mathrm{C}$. Results of these measurements are used to test two mathematical representations based upon the combined nearly ideal binary solvent (NIBS)/Redlich-Kister equation and modified Wilson model. For the systems studied, the combined NIBS/Redlich-Kister provided the better mathematical representations, with deviations between experimental and back-calculated values being on the order of $\pm 1.5 \%$ or less in the case of the three-parameter form. Slightly larger deviations of were noted for the modified Wilson mathematical representation.
\end{abstract}

\section{Introduction}

Solid-liquid equilibrium data of organic nonelectrolyte systems are becoming increasingly important in the petroleum industry, particularly in light of present trends toward heavier feedstocks and known carcinogenicity/ mutagenicity of many of the larger polycyclic aromatic compounds. Solubility data for a number of polycyclic aromatic hydrocarbons (i.e., anthracene and pyrene) and heteroatom polynuclear aromatics (i.e., carbazole, dibenzothiophene, and xanthene) have been published in the recent chemical literature (for listing of references, see: Acree, 1994, 1995, and in press). Despite efforts by experimentalists and scientific organizations, both in terms of new experimental measurements and critically-evaluated data compilations, there still exist numerous systems for which actual solubility data are not readily available.

To address this problem, researchers have turned to group contribution methods and semiempirical expressions to predict desired quantities. Group contribution methods have proved fairly successful in estimating solid solubility in pure and binary solvent mixtures from structural information. Practical application though, is limited to systems for which all group interaction parameters are known. Generally, interaction parameters are evaluated from solid-liquid and liquid-vapor equilibria data. It is important that measurements be made on compounds containing as many different functional groups as possible, preferably with adequate representation from both monoand multifunctional solute/solvent molecules to permit evaluation of potential synergistic effects. It is essential to make measurements near infinite dilution in the event that one wishes to determine separate interaction parameters for finite concentration and infinite dilution activity coefficient predictions.

Continued development of soiution models for describing the thermodynamic properties of a solute in binary solvent systems requires that a large data base be available for assessing the applications and limitations of derived expressions. Currently, only a limited data base exists for the solubility of crystalline nonelectrolyte in binary solvent mixtures. For this reason, anthracene solubilities were determined in seven binary alcohol + dibutyl ether solvent mixtures. Results of these measurements are used to

To whom correspondence should be addressed. E-mail: acree@casl.unt.edu.
Table 1. Experimental Mole Fraction Solubilities of Anthracene (A) in Binary Alcohol (B) + Dibutyl Ether (C) Solvent Mixtures at $25.0^{\circ} \mathrm{C}$

\begin{tabular}{|c|c|c|c|}
\hline$x_{\mathrm{C}}^{0}$ & $x_{\mathrm{A}}^{\mathrm{sat}}$ & $x_{\mathrm{C}}^{0}$ & $x_{\mathrm{A}}^{\mathrm{sat}}$ \\
\hline \multicolumn{4}{|c|}{ 1-Propanol (B) + Dibutyl Ether $(\mathrm{C})$} \\
\hline 0.0000 & 0.000591 & 0.3948 & 0.002175 \\
\hline 0.0532 & 0.000787 & 0.6368 & 0.003018 \\
\hline 0.0984 & 0.000961 & 0.8042 & 0.003409 \\
\hline 0.2230 & 0.001463 & 1.0000 & 0.003615 \\
\hline 0.3074 & 0.001784 & & \\
\hline \multicolumn{4}{|c|}{ 2-Propanol (B) + Dibutyl Ether (C) } \\
\hline 0.0000 & 0.000411 & 0.4112 & 0.001989 \\
\hline 0.0517 & 0.000570 & 0.6286 & 0.002827 \\
\hline 0.1011 & 0.000750 & 0.7938 & 0.003267 \\
\hline 0.2268 & 0.001226 & 1.0000 & 0.003615 \\
\hline 0.3126 & 0.001609 & & \\
\hline \multicolumn{4}{|c|}{ 1-Butanol $(B)+$ Dibutyl Ether $(C)$} \\
\hline 0.0000 & 0.000801 & 0.4627 & 0.002513 \\
\hline 0.0564 & 0.001004 & 0.6851 & 0.003259 \\
\hline 0.1215 & 0.001246 & 0.8369 & 0.003526 \\
\hline 0.2719 & 0.001822 & 1.0000 & 0.003615 \\
\hline 0.3541 & 0.002085 & & \\
\hline \multicolumn{4}{|c|}{ 2-Butanol (B) + Dibutyl Ether (C) } \\
\hline 0.0000 & 0.000585 & 0.3916 & 0.002085 \\
\hline 0.0642 & 0.000807 & 0.6777 & 0.003067 \\
\hline 0.1203 & 0.001019 & 0.7413 & 0.003211 \\
\hline 0.2536 & 0.001544 & 1.0000 & 0.003615 \\
\hline 0.3457 & 0.001901 & & \\
\hline \multicolumn{4}{|c|}{ 2-Methyl-1-propanol (B) + Dibutyl Ether (C) } \\
\hline 0.0000 & 0.000470 & 0.4450 & 0.002093 \\
\hline 0.0627 & 0.000668 & 0.6767 & 0.002936 \\
\hline 0.1127 & 0.000837 & 0.8164 & 0.003345 \\
\hline 0.2427 & 0.001323 & 1.0000 & 0.003615 \\
\hline 0.3429 & 0.001693 & & \\
\hline \multicolumn{4}{|c|}{ 3-Methyl-1-butanol (B) + Dibutyl Ether (C) } \\
\hline 0.0000 & 0.000727 & 0.4656 & 0.002350 \\
\hline 0.0753 & 0.000964 & 0.6713 & 0.003026 \\
\hline 0.1270 & 0.001142 & 0.7950 & 0.003343 \\
\hline 0.2884 & 0.001737 & 1.0000 & 0.003615 \\
\hline 0.3892 & 0.002076 & & \\
\hline \multicolumn{4}{|c|}{ 1-Octanol $(B)+$ Dibutyl Ether $(C)$} \\
\hline 0.0000 & 0.002160 & 0.5892 & 0.003459 \\
\hline 0.0964 & 0.002415 & 0.7847 & 0.003792 \\
\hline 0.1982 & 0.002665 & 0.8897 & 0.003722 \\
\hline 0.3832 & 0.003114 & 1.0000 & 0.003615 \\
\hline
\end{tabular}

further test the descriptive abilities of several previously derived expressions. 
Table 2. Mathematical Representation of Anthracene Solubilities in Several Binary Alcohol (B) + Dibutyl Ether (C) Solvent Mixtures

\begin{tabular}{|c|c|c|c|c|c|c|}
\hline \multirow{2}{*}{$\begin{array}{c}\text { binary solvent system } \\
\text { component }(B)+\text { component }(C)\end{array}$} & \multicolumn{2}{|c|}{ 2-Par eq 1} & \multicolumn{2}{|c|}{ 3-Par eq 1} & \multicolumn{2}{|c|}{ eq 2} \\
\hline & $S_{\mathrm{i}}^{\mathrm{a}}$ & $\% \operatorname{dev}^{b}$ & $S_{i}{ }^{a}$ & $\% \operatorname{dev}^{b}$ & $\Lambda_{\mathrm{ij}}^{\mathrm{adj} c}$ & $\% \operatorname{dev}^{b}$ \\
\hline 1-propanol + dibutyl ether & $\begin{array}{l}2.396 \\
0.986\end{array}$ & 2.3 & $\begin{array}{l}2.167 \\
0.931 \\
0.891\end{array}$ & 1.1 & $\begin{array}{r}3.268 \\
10.096\end{array}$ & 1.6 \\
\hline 2-propanol + dibutyl ether & $\begin{array}{l}2.796 \\
1.519\end{array}$ & 2.8 & $\begin{array}{l}2.588 \\
1.235 \\
0.866\end{array}$ & 0.8 & $\begin{array}{r}3.436 \\
10.096\end{array}$ & 1.6 \\
\hline 1-butanol + dibutyl ether & $\begin{array}{l}1.894 \\
0.616\end{array}$ & 2.2 & $\begin{array}{l}1.736 \\
0.488 \\
0.574\end{array}$ & 0.9 & $\begin{array}{r}2.948 \\
10.096\end{array}$ & 1.9 \\
\hline 2-butanol + dibutyl ether & $\begin{array}{l}2.259 \\
1.103\end{array}$ & 2.2 & $\begin{array}{l}2.109 \\
0.849 \\
0.726\end{array}$ & 0.3 & $\begin{array}{r}3.172 \\
10.096\end{array}$ & 1.3 \\
\hline 2-methyl-1-propanol - dibutyl ether & $\begin{array}{l}2.477 \\
1.170\end{array}$ & 3.0 & $\begin{array}{l}2.231 \\
0.932 \\
0.927\end{array}$ & 0.6 & $\begin{array}{r}3.028 \\
10.096\end{array}$ & 1.0 \\
\hline 3-methyl-1-butanol + dibutyl ether & $\begin{array}{l}1.771 \\
0.560\end{array}$ & 1.1 & $\begin{array}{l}1.694 \\
0.464 \\
0.338\end{array}$ & 0.3 & $\begin{array}{r}2.708 \\
10.096\end{array}$ & 1.3 \\
\hline 1-octanol + dibutyl ether & $\begin{array}{l}0.761 \\
0.138\end{array}$ & 2.2 & $\begin{array}{r}0.712 \\
-0.143 \\
0.169\end{array}$ & 0.6 & $\begin{array}{r}2.824 \\
10.096\end{array}$ & 2.0 \\
\hline
\end{tabular}

${ }^{a}$ Combined NIBS/Redlich-Kister curve-fit parameters are ordered as $S_{0}, S_{1}$, and $S_{2} \cdot{ }^{b}$ Deviation $(\%)=(100 / N) \sum \mid \ln \left[\left(x_{\mathrm{A}}^{\mathrm{sat}}\right)\right.$ calc/ $\left.\left(x_{\mathrm{A}}^{\text {sat }}\right)^{\text {exp }}\right]$. ${ }^{c}$ Adjustable parameters for the modified Wilson equation are ordered as $\Lambda_{\mathrm{BC}}^{\text {adj }}$ and $\Lambda_{\mathrm{CB}}^{\text {adj }}$.

\section{Experimental Methods}

Anthracene (Aldrich 99.9+\%) was used as received. Dibutyl ether (Aldrich $99+\%$, anhydrous) was stored over molecular sieves before use. 1-Propanol (Aldrich 99+\%, anhydrous), 2-propanol (Aldrich $99+\%$, anhydrous), 1-butanol (Aldrich HPLC, 99.8+\%), 2-butanol (Aldrich 99+\%, anhydrous), 2-methyl-1-propanol (Aldrich 99+\%, anhydrous), 3-methyl-1-butanol (Aldrich 99+\%, anhydrous), and 1-octanol (Aldrich 99+\%, anhydrous) were stored over both anhydrous sodium sulfate and molecular sieves before being fractionally distilled. Gas chromatographic analysis showed solvent purities to be $99.7 \mathrm{~mol} \%$ or better. Karl Fischer titration gave water contents (mass/mass \%) of $<0.01 \%$ for all seven alcohols used. Binary solvent mixtures were prepared by mass so that compositions could be calculated to 0.0001 mole fraction.

Excess solute and solvent were placed in amber glass bottles and allowed to equilibrate in a constant temperature water bath at $25.0 \pm 0.1{ }^{\circ} \mathrm{C}$ for several days. Attainment of equilibrium was verified by repetitive measurements after several additional days and by approaching equilibrium from supersaturation by preequilibrating the solutions at a higher temperature. Aliquots of saturated anthracene solutions were transferred through a coarse filter into a tared volumetric flask to determine the amount of sample and diluted quantitatively with methanol. Concentrations were determined spectrophotometrically at 356 $\mathrm{nm}$ on a Bausch and Lomb Spectronic 2000. Experimental anthracene solubilities in the seven binary alcohol + dibutyl ether mixtures studied are listed in Table 1. Numerical values represent the average of between four and eight independent determinations, with the measured values being reproducible to within $=1.3 \%$.

\section{Results and Discussion}

Acree and co-workers (Acree and Zvaigzne, 1991; Acree et al., 1991; Acree, 1992) suggested possible mathematical representations for isothermal solubility data based upon either a combined NIBS/Redlich-Kister model

$$
\begin{array}{r}
\ln x_{\mathrm{A}}^{\mathrm{sat}}=x_{\mathrm{B}}^{0} \ln \left(x_{\mathrm{A}}^{\mathrm{sat}}\right)_{\mathrm{B}}+x_{\mathrm{C}}^{0} \ln \left(x_{\mathrm{A}}^{\mathrm{sat}}\right)_{\mathrm{C}}+ \\
x_{\mathrm{B}}^{0} x_{\mathrm{C}}^{0} \sum_{i=0}^{N} S_{i}\left(x_{\mathrm{B}}^{0}-x_{\mathrm{C}}^{0}\right)^{i}
\end{array}
$$

or modified Wilson equation (Comer and Kopecni, 1990)

$$
\begin{gathered}
\ln \left[a_{\mathrm{A}}(s) / x_{\mathrm{A}}^{\mathrm{sat}}\right]=1-x_{\mathrm{B}}^{0}\left\{1-\ln \left[a_{\mathrm{A}}(\mathrm{s}) /\left(x_{\mathrm{A}}^{\mathrm{sat}}\right)_{\mathrm{B}}\right]\right\} /\left(x_{\mathrm{B}}^{\circ}+\right. \\
\left.x_{\mathrm{C}}^{\mathrm{o}} \Lambda_{\mathrm{BC}}^{\mathrm{adj}}\right)-x_{\mathrm{C}}^{0}\left\{1-\ln \left[a_{\mathrm{A}}(\mathbf{s}) /\left(x_{\mathrm{A}}^{\mathrm{sat}}\right)_{\mathrm{C}}\right]\right\} /\left(x_{\mathrm{B}}^{\circ} \Lambda_{\mathrm{CB}}^{\mathrm{adj}}+x_{\mathrm{C}}^{\mathrm{o}}\right)
\end{gathered}
$$

where the various $S_{i}$ and $\Lambda_{\mathrm{ij}}^{\mathrm{adj}}$ "curve-fit" parameters can be evaluated via least squares analysis. In eqs 1 and 2 $x_{\mathrm{B}}^{0}$ and $x_{\mathrm{C}}^{0}$ refer to the initial mole fraction composition of the binary solvent calculated as if the solute were not present, $a_{\mathrm{A}}(\mathrm{s})$ is the activity of the solid solute, and $\left(x_{\mathrm{A}}^{\text {sat }}\right)_{i}$ is the saturated mole fraction solubility of the solute in pure solvent $i$. The numerical value of $a_{\mathrm{A}}(\mathrm{s})=0.01049$ (Acree and Rytting, 1983) used in the modified Wilson computations was calculated from

$$
\ln a_{\mathrm{A}}(s)=-\Delta_{\mathrm{fus}} H_{\mathrm{A}}\left(T_{\mathrm{mp}}-T\right) /\left(R T T_{\mathrm{mp}}\right)
$$

the molar enthalpy of fusion, $\Delta_{\text {fus }} H_{\mathrm{A}}$, at the normal melting point temperature of the solute, $T_{\mathrm{mp}}$.

The ability of eqs 1 and 2 to mathematically represent the experimental solubility of anthracene in the seven binary alcohol + dibutyl ether solvent systems is summarized in Table 2 in the form of curve-fit parameters and percent deviations in back-calculated solubilities. Careful examination of Table 2 reveals that the three-parameter form of the combined NIBS/Redlich-Kister equation provided the better mathematical description for how the solubility of anthracene varies with solvent composition. For the most part, back-calculated and experimental values differ by less than $\pm 1.5 \%$, which is comparable to the experimental uncertainty. Slightly larger deviations were noted in the case of the modified Wilson equation.

From a computational standpoint, eq 1 will likely be preferred because most research groups involved in reporting thermodynamic properties have computer programs for 
evaluating the Redlich-Kister coefficients. With this idea in mind, we recommend that the future presentation of experimental isothermal solubility data for slightly soluble solid solutes dissolved in binary solvent mixtures include not only a tabulation of the actual observed values but, if possible, that the solubility data be mathematically represented by eq 1 . Realizing that a single equation will not be applicable to all systems encountered, we further suggest eq 2 as an alternative mathematical representation for systems having extremely large solubility ranges and or highly asymmetrical $\ln x_{A}^{\text {sat }}$ versus $x_{B}^{0}$ curves, such as the carbazole + alkane + tetrahydropyran systems reported previously (Acree et al., 1991).

\section{Literature Cited}

Acree, W. E., Jr. Mathematical Representation of Thermodynamic Properties. Part 2. Derivation of the Combined Nearly Ideal Binary Solvent (NIBS)/Redlich-Kister Mathematical Representation from a Two-Body and Three-Body Interactional Mixing Model. Thermochim. Acta 1992, 198, 71-79.

Acree, W. E., Jr. Polycyclic Aromatic Hydrocarbons in Pure and Binary Solvents. Volume 54 in IUPAC Solubility Data Series: Oxford University Press: Oxford, United Kingdom, 1994.

Acree, W. E.. Jr. Polycyclic Aromatic Hydrocarbons: Binary Nonaque. ous Systems: Part 1 (Solutes A-E). Volume 58 in IUPAC Solubility
Data Series: Oxford University Press: Oxford, United Kingdom, 1995.

Acree, W. E., Jr. Polycyclic Aromatic Hydrocarbons: Binary Nonaque. ous Systems: Part 2 (Solutes F-Z). Volume 59 in IUPAC Solubility Data Series; Oxford University Press: Oxford, United Kingdom, in press.

Acree, W. E., Jr.; Rytting, J. H. Solubility in Binary Solvent Systems III: Predictive Expressions Based on Molecular Surface Areas. $J$. Pharm. Sci. 1983, 72, 292-296.

Acree, W. E., Jr.; Zvaigzne, A. I. Thermodynamic Properties of Nonelectrolyte Solutions. Part 4. Estimation and Mathematical Representation of Solute Activity Coefficients and Solubilities in Binary Solvents Using the NIBS and Modified Wilson Equations. Thermochim. Acta 1991, 178, 151-167.

Acree, W. E. Jr.; McCargar, J. W.; Zvaigzne, A. I.; Teng, I.-L. Mathematical Representation of Thermodynamic Properties. Carbazole Solubilities in Binary Alkane - Dibutyl Ether and Alkane + Tetrahydropyran Solvent Mixtures. Phys. Chem. Liq. 1991, 23, $27-35$.

Comer, J. F.; and Kopecni, M. M. Prediction of Gas Chromatography Solute Activity Coefficients in Mixed Stationary Phases Based on the Wilson Equation. Anal. Chem. 1990, 62, 991-994.

Received for review January 9, 1995. Accepted March 25, $1995 .^{8}$

JE950006H

${ }^{8}$ Abstract published in Advance ACS Abstracts, June 1, 1995. 